\title{
ВЫСЫЛКА (ДЕПОРТАЦИЯ) МИГРАНТОВ В СВЕТЕ ЗАЩИТЫ ПРАВА НА УВАЖЕНИЕ СЕМЕЙНОЙ ЖИЗНИ В ЕВРОПЕЙСКОМ СУДЕ ПО ПРАВАМ ЧЕЛОВЕКА
}

\begin{abstract}
Аннотация: В данной статье рассматривается практика Европейского Суда по правам человека по делам о нарушении статьи 8 Европейской Конвенции о защите прав человека и основных свобод, гарантирующей, в частности право на уважение семейной жизни. Осуществляемая наџиональными властями государств-участников Совета Европы высылка(депортация) мигрантов нередко приводит к нарушению указанного выше права, что влечет обращение лица в ЕСПЧ. Проведен краткий анализ позищии Европейского Суда,его руководящих принципов, в отношении действий наџиональных властей, существующей правовой базы и толкования права, гарантируемого статьей 8 Европейской Конвенции.
\end{abstract}

Ключевые слова: Юриспруденция, Европейский Суд, Европейская Конвенция, Статья 8, Мигранты, Депортация, Права, Нарушение, Семейная, Защита

реди лиц, пользующихся международной защитой, одной из наиболее незащищенных категорий являются иностранные лица на территории страны пребывания. Находясь в стране на законных основаниях, мигранты нередко подвергаются необоснованной высылке, поводом к которой являются нарушения ими отдельных норм национального законодательства. Данные обстоятельства влекут нарушение прав и свобод человека, гарантированных Европейской Конвенции о защите прав человека и основных свобод 1950 г. (далее - ЕКПЧ), последствием чего становятся обращения за международными средствами правовой защиты, в частности в Европейский Суд по правам человека (далее ЕСПЧ).

В Европейской Конвенции о защите прав человека и основных свобод 1950 г. не раз идет речь о гарантиях, предоставляемых в той или иной степени столь незащищенным в правовом аспекте лицам (например, право иностранца не быть высланным из страны, если он находится легально на территории этой страны и если его высылка не обусловлена соображениями национальной безопасности ${ }^{1}$, защита от произвола государственных органов при задержании с целью высылки из страны, а также на период рассмотрения требования о предоставлении убежища, право в любое время оспорить законность такого задержания в судебном порядке со всеми необходимыми процессуальными гарантиями и потребовать освобождения²),

\footnotetext{
${ }^{1}$ Протокол № 7 к Европейской Конвенции о защите прав и основных свобод человека и гражданина 1950 г. // http://www.echr.ru/ documents/doc/2440800/2440800-001.htm

${ }^{2}$ Статья 5 Европейской Конвенции о защите прав и основных свобод человека и гражданина 1950 г.// http://www.echr.ru/documents/ doc/2440800/2440800-001.htm
}

однако положения статьи 8 не содержат специальных уточнений, дополнений, даже упоминания о какихлибо специальных правах мигрантов.

Несмотря на то, что статья 8 ЕКПЧ, с учетом вышеизложенного, не содержит абсолютного права для любой категории иностранцев не быть высланными, прецедентное право Европейского Суда широко демонстрирует, что существуют обстоятельства, при которых высылка иностранца может привести к нарушению этой статьи ${ }^{3}$. В деле Унер против Нидерландов ${ }^{4}$ Европейский Суд разработал соответствующие критерии, которые будут использоваться для определения того, была ли высылка необходимой мерой в демократическом обществе, пропорциональной преследуемой цели (так называемые, критерии Унера). К ним относятся:

- характер и серьезность совершенного заявителем преступления;

- продолжительность пребывания заявителя в стане, откуда его или ее высылают;

- время, прошедшее с момента совершения преступления и поведение заявителя во время этого периода;

- гражданство людей, о которых идет речь;

- семейная ситуация заявителя, а именно - продолжительность брака и другие факторы, отображающие качество семейной жизни;

- знал ли второй супруг о совершенном правонарушении в момент заключения брака;

\footnotetext{
${ }^{3}$ Для примера см. решения в делах Мустафим против Бельгии, Белджоуди против Франции, Амроллахи против Дании, № 56811/00, от 11 июля 2002 г.; Вильмаз против Германии, № 52853/99, от 17 апреля 2003 г;; и Келес против Германии, № 32231/02, от 27 октября 2005 г.

${ }^{4}$ Постановление Европейского Суда по делу «Унер против Нидерландов» (Oner v. the Netherlands) от 16 июня 2005 г. (46410/99)
} 
- есть ли в браке дети, если есть, их возраст; и

- серьезность трудностей, с которыми может столкнуться супруг в стране, куда планируется высылка заявителя.

Достаточно показательным в плане демонстрации позиции ЕСПЧ по вопросу применения статьи 8 в области защиты прав мигрантов является дело «Лю и Лю против Российской Федерации» 5 .

Заявители обжалуют нарушение российскими властями статьи 8 ЕКПЧ, выразившееся, по их мнению, в отказе властей предоставить первому заявителю вид на жительство и в принятии последующего решения властей Российской Федерации о депортации его в Китай. В обоснование своих требований заявители ссылались на то, что первый заявитель проживал в России с 1994 года, что женившись на гражданке России, и будучи отцом двоих детей, он вел семейную жизнь в России.

Отказ российских властей предоставить первому заявителю право на постоянное проживание в России и решение о его депортации, по мнению заявителей, воспрепятствовало их семейной жизни.

В своем решении Европейский Суд, во-первых, определил, что государство имеет широкие полномочия по установлению порядка контроля въезда мигрантов, их проживания. Статья 8 в свою очередь не налагает на государство обязательство уважать выбор семейными парами страны их совместного проживания, и разрешать воссоединение семей на своей территории, и, тем более, не гарантирует право на получение конкретных форм разрешения на проживание, то есть государство само определяет предоставление какого статуса будет достаточным для свободного осуществления гарантируемых прав. Однако принятое решение о депортации может нарушить (что просматривается в данном деле) право на семейную и частную жизнь заявителей.

Во-вторых, национальное законодательство обязано предоставить возможность правовой защиты, нарушенных прав и гарантированность возможность оспорить неправомерные действия государственных органов и должностных лиц, даже в условиях использования в качестве обоснования решения о высылке информации, составляющей государственную тайну и не подлежащих разглашению. По мнению Европейского Суда, государство должно предусмотреть систему сдержек и противовесов в процессе исследования доказательств наличия угрозы национальной безопасности посредством, например, создания независимого контролирующего органа.

\footnotetext{
5 Постановление Европейского Суда по делу «Лю и Лю против Российской Федерации» (Liu v Russia) от 6 декабря 2007 г. (№ 42086/05) // http://www.minjust.ru/ru/ECJ/precedent/index. php?id4 $=330$
}

Несмотря на то, что в большинстве жалоб ЕСПЧ признает требования заявителей обоснованными и устанавливает наличие нарушения статьи 8 при осуществлении высылки мигрантов, нередки случаи оправдания целей депортации. В таких случаях Европейский Суд отталкивается от применимости положений части 2, рассматриваемой статьи ЕКПЧ, в каждом конкретном деле.

Продолжая тему семейных отношений, следует отметить, что прочность связей со страной пребывания и степень зависимости от нее остальных членов семьи, может оказать свое влияние на исход дела. Как правило, нарушение пункта 1 статьи 8 Конвенции не признается в тех случаях, когда можно ожидать, что члены семьи последуют за высылаемым лицом.

В частности, подобное ожидание оправдано, когда и высылаемый, и члены его семьи являются гражданами страны депортации и не существует правовых препятствий для их возвращения туда.

При этом считается, что члены семьи высылаемого могут последовать за ним в страну депортации, гражданами которой они являются или с которой они имеют устойчивые связи, даже в том случае, если уровень заработной платы и образования в данной стране ниже, чем в стране проживания. Вместе с тем вряд ли можно ожидать, что члены семьи последуют за высылаемым лицом, если они интегрированы в стране проживания, в частности являются ее гражданами ${ }^{6}$.

Изначально, высылка, связанная с осуждением за преступления любой категории, во всех случаях признавалась необходимой в демократическом обществе в интересах предотвращения преступлений и защиты прав и свобод других лиц. Впоследствии акцент был сделан на тяжесть преступления, совершенного высылаемым лицом. Как правило, вмешательство признавалось оправданным в случае осуждения лица за телесные повреждения, грабеж, преступления, связанные с наркотиками. В последнем случае вмешательство признавалось оправданным и с точки зрения интересов охраны здоровья.

Безусловным является тот факт, что нарушение сроков пребывания лица на территории страны, умышленный обман иммиграционных властей, «пренебрежение» им-

\footnotetext{
${ }^{6}$ В Постановление Европейского Суда по делу «Бельджуди против Франции» (Beldjoudi v. France) от 26 марта 1992 г. (№ 12083/86) он отмечал, что если бы г-жа Бельджуди, родившаяся во Франции, от родителей-французов, всю жизнь проживавшая во Франции и имевшая французское гражданство, последовала за своим мужем после его высылки из страны, то ей пришлось бы обосноваться за границей, вероятнее всего в Алжире, в государстве, язык которого она скорее всего не знает. По мнению Суда, такая резкая смена обстановки могла бы создать ей значительные трудности, вызвать необходимость адаптироваться к новым условиям и породила бы реальные препятствия практического и даже юридического плана. // http://infopravo.by.ru/fed1992/ch03/akt14352.shtm
} 


\section{Право и политика $2(158) \cdot 2013$}

миграционным контролем, невыполнением предписаний о депортации, подделка документов и другие противозаконные действия могут служить практически абсолютным оправданием депортации (высылки) и обосновывается необходимостью предотвращения беспорядков. Ранее в решениях Европейской Комиссии по правам человека было определено, что не существует таких аспектов семейной жизни, которые могут перевесить интересы должного осуществления иммиграционного контроля

Европейский Суд признает достаточным основанием для высылки иностранцев, совершивших серьезные правонарушения, интересы предотвращения беспорядков или преступлений, за исключением тех случаев, когда речь шла о втором поколении мигрантов. При рассмотрении подобных дел существенное значение имели такие факторы, как срок проживания в данной стране, наличие связей со страной происхождения, суровость последствий в случае депортации.

Так, в решении по делу «Абдулазиз, Кабалез и Балкандали против Соединенного Королевства» ${ }^{8}$ Европейский Суд подтвердил, что право иностранца на въезд и пребывание в стране как таковое не гарантируется Европейской Конвенцией, однако иммиграционный контроль должен осуществляться в соответствии с обязательствами, принятыми при подписании ЕКПЧ, и при высылке лица из государства, в котором проживают члены его семьи, может встать вопрос о соответствии данной меры статье 8 Конвенции 9 .

Суд признал, что положения данной статьи нельзя рассматривать как общее обязательство государства-участника Конвенции уважать право семейной пары выбирать страну проживания семьи и принимать на свою территорию супругов, не являющихся гражданами страны.

Судьи сочли, что в данном деле заявительницы не продемонстрировали убедительные доказательства того, что существуют препятствия для ведения семейной жизни в странах, гражданами которых они являются, или в странах

\footnotetext{
${ }^{7}$ Европейский Суд не всегда придерживается подобных подходов. В Постановлении Европейского Суда по делу «Беррехаб против Нидерландов» ((Berrehab v Netherlands) от 21 июня 1988 г. (№ 10730/84) // Информационная система по документам по правам человека и тематическим публикациям / http://www.echr-base.ru/ berrehab.jsp) ЕСПЧ признал, что высылка заявителя соответствовала иммиграционной политике страны, однако действия властей не были признаны «необходимыми в демократическом обществе», поскольку отказ в выдаче нового вида на жительство и последующая высылка из страны грозили разрывом отношений между отцом и дочерью. В данном деле, заявитель жил в стране на законных основаниях в течение ряда лет, имел дом и работу, создал семью.

${ }^{8}$ Постановление Европейского Суда по делу «Абдулазиз, Кабалез и Балкандали против Соединенного Королевства» от 28 мая 1985 г. (№ 9214/80; 9473/81; 9474/81) // http://www.ourcourt.ru/practice/ feder18/pr18348.htm

9 Там же $\S 59$.
}

происхождения их супругов, а также особые обстоятельства, не позволяющие ожидать от них подобных действий.

Европейский Суд придерживается мнения, что при осуществлении высылки (депортации) государство должно учитывать, что высылаемое лицо может быть подвергнуто жестокому обращению, пыткам, уголовному преследованию и др., учитыввая фундаментальное значение прав, гарантированных положениями статей 2 и 3 ЕКПЧ $\Psi^{10}$.

Однако подобного рода насущные соображения не возникают автоматически в контексте других норм Европейской Конвенции. С чисто прагматической точки зрения нельзя требовать, чтобы государство - участник Европейской Конвенции, осуществляющчее высылку того или иного лииа, возврашало бы иностранца только в ту страну, где полностью и эффективно соблюдаются все права и свободы человека, закрепленные в ЕКПЧ ${ }^{11}$.

В процессе рассмотрения материалов каждой жалобы Европейский Суд обязан учесть все обстоятельства, имеющие значение для дела. При этом категория таких дел имеет специфические особенности относительно установления некоторых фактов. У ЕСПЧ сложились определенные подходы к рассмотрению дел, связанных с вмешательством в осуществление права на уважение семейной жизни при высылке (депортации). Универсальное определение понятия «семейной жизни» сформулировать практически невозможно. Но без доказательства наличия или отсутствия эффективных и тесных социальных, родственных и семейных связей между лицом, подлежащим высылке, и другими членами семьи - зачастую нельзя предопределить исход дела.

Как правило, семейная жизнь предполагает совместное проживание мужа и жены. Пары, не состоящие в браке, должны проживать совместно в течение достаточно длительного времени. В случае раздельного проживания необходимо доказать существование тесных связей между членами семьи, что предполагает либо регулярные контакты друг с другом, либо наличие близких родственных отношений. Финансовая зависимость также может иметь существенное значение.

\footnotetext{
${ }^{10}$ Статья 2, в частности, гарантирует, что «право каждого лица на жизнь охраняется законом, никто не может быть умышленно лишен жизни иначе как во исполнение смертного приговора, вынесенного судом за совершение преступления, в отношении которого законом предусмотрено такое наказание»; а Статья 3 ЕКПЧ говорит о том, что «никто не должен подвергаться ни пыткам, ни бесчеловечному или унижающему достоинство обращению или наказанию»./ Европейская Конвенция о защите прав человека и основных свобод // http://www.coe.ru/main/echr/

${ }^{11}$ Постановление Европейского Суда по делу «Фашками против Соединенного Королевства» (Fashkami v United Kingdom) от 22 июня 2004 г. (№ 17341/03) // Бюллетень Европейского Суда по правам человека № 11/2004.
} 
К примеру, это могут быть отношения между ребенком и его родителями, а точнее, необходимость их постоянного общения, прекращение которого (в том числе посредством депортации), по мнению Европейского Суда, является абсолютно неприемлемым в свете, гарантий предоставленных статьей 8 ЕКПЧ ${ }^{12}$.

Распоряжение о депортации кого-либо из страныучастницы, где проживают дети этого человека или люди, с которыми у него есть право на семейную жизнь, или отказ одному из родителей и другим членам семьи соединиться с другими членами семьи в этом государстве, будет означать вмешательство в их семейную жизнь в рамках статьи 8 ЕКПЧ, и, может быть, совместима с Конвенцией только при выполнении требований ч. 2 статьи 8 ЕКПЧ ${ }^{13}$.

Подобный вопрос был рассмотрен Европейским Судом по существу в ряде других дел. В деле «Мехеми против Франции» $»^{14}$ ЕСПЧ констатировал нарушение статьи 8 ЕКПЧ вследствие высылки алжирского подданного из Франции, из-за чего он был оторван от семьи и детей, оставшихся в этой стране. В решении, вынесенном по делу «Эль Буджайди против Франции» ${ }^{15}$, Европейский Суд счел, что высылка заявителя в Марокко, повлекшая его отрыв от семьи и родственников, оставшихся во Франции, не составляет нарушения статьи 8 ЕКПЧ.

Совместное прочтение вынесенных Европейским Судом решений по вышеуказанным делам дает представление о пределах дозволенного статьей 8 ЕКПЧ вмешательства государства в право на личную и семейную жизнь лица в результате его высылки из страны.

Причиной для высылки обоих заявителей стали совершенные ими преступления, связанные с торговлей наркотиками. В деле Мехеми заявитель являлся уроженцем Франции, прожившим всю свою жизнь в этой стране и много лет назад основавший семью, все члены которой были французскими гражданами. При этом заявитель не

${ }^{12}$ Постановление Европейского Суда по делу «Берехаб против Нидерландов» («Berrehab v Netherlands») от 21 июля 1988 г. (№ 10730/84) // Информационная система по документам по правам человека и тематическим публикациям / http:/www.echr-base.ru

${ }^{13}$ Европейская конвенция о защите прав человека и основных свобод. Статья 8 Право на уважение частной и семейной жизни, жилища и корреспонденции. Прецеденты и комментарии. /Урсула Килкэли; пер с англ. Е.А. Чефранова, Москва, 2001.

${ }^{14}$ Постановление Европейского Суда по делу «Мехеми против Франции» (Mehemi v France) от 26 сентября 1997 г. (№ 25017/94) // Бюллетень Европейского Суда по правам человека. Российское издание № 9/2003 г. (см. также Постановление Европейского Суда по делу «Мустаким против Бельгии» («Moustaquim v Belgium») от 18 февраля 1991 г. (№ 12313/86) // http://www.ourcourt.ru/practice/ feder18/pr18371.htm)

${ }^{15}$ Постановление Европейского Суда по делу «Эль Буджайди против Франции» (El Boujaidi v France) от 26 сентября 1996 г. (№ 25613/94) // http://cmiskp.echr.coe.int/tkp197/portal.asp?sessionI $\mathrm{d}=52615535 \&$ skin $=$ hudoc-en\&action=request имел никаких социальных связей в Алжире, гражданином которого он по-прежнему являлся. ЕСПЧ учел, что решение о высылке заявителя, безусловно, преследовало законную цель охраны здоровья общества и предотвращения преступлений, связанных с торговлей наркотиками. Однако, учитывая особо крепкие семейные и социальные связи заявителя во Франции и полное отсутствие таковых в Алжире, Европейский Суд пришел к выводу, что столь серьезное вмешательство в семейную жизнь заявителя не было пропорциональным преследуемой законной цели и, соответственно, необходимым в смысле части 2 статьи 8 Европейской Конвенции ${ }^{16}$.

В деле Эль Буджайди сложилась несколько иная ситуация. Заявитель тоже постоянно проживал во Франции, но только с возраста семи лет. Часть родственников заявителя проживали во Франции, но при этом он никогда не терял полной связи со страной своего происхождения, Марокко, в которую возвращался периодически и где, в частности, проходил военную службу. И, наконец, связь, которую он имел со своей сожительницей, была установлена уже после совершения преступления, то есть была достаточно поздней. В этом деле ЕСПЧ рассмотрел вопрос о пропорциональности вмешательства в право заявителя на личную и семейную жизнь законной цели предотвращения преступлений, связанных с торговлей наркотиками. ЕСПЧ пришел к выводу, что, учитывая более слабые связи заявителя с Францией и наличие некоторых социальных связей в Марокко, оно было пропорциональным, а значит необходимым в смысле части 2 статьи 8 ЕКПЧ.

Следует особо отметить тот факт, что, несмотря на присуждение Европейским Судом определенной денежной компенсации заявителям, высланным или подлежащим высылке в нарушение Европейской Конвенции, эта компенсация сама по себе никак не может устранить практические последствия высылки. Так, в вышеупомянутом деле «Мехеми против Франции», присужденное ЕСПЧ возмещение моральный ущерб в размере 60 тысяч французских франков (около 10 тысяч долларов) еще не компенсировало тот факт, что в отношении заявителя продолжало действовать запрещение на въезд в страну, где находилась вся его семья, то есть жена, дети, родственники.

Исполнение решения Европейского суда в этом деле, таким образом, потребовало от Франции принятия необходимых мер, обеспечивающих возвращение заявителя в страну с тем, чтобы исправить допущенное в отношении него нарушение. В процессе исполнения решения в этом

\footnotetext{
${ }^{16}$ Материалы девятого семинара, проведенного Правозащитным центром «Мемориал» о программе «Миграция и Право»; «Права беженцев в свете гарантий, предусмотренных в Европейской Конвенции по правам человека» М. Б. Лобов ПЦ «Мемориал» M., 2001 г., с .111// http://refugee.memo.ru /site/seminars.nsf/ MainFrame1?OpenFrameSet
} 


\section{Право и политика $2(158) \cdot 2013$}

деле заявитель в короткие сроки получил в административном порядке разрешение на въезд во Францию, проживание со своей семьей и право на работу. Приговор суда, запрещающий бессрочный запрет въезда заявителя в страну, также был пересмотрен.

В 2010 году было вынесено еще одно решение по данной категории жалоб против Российской Федерации. Выходец из Узбекистана Абдугани Камалиев был выдворен из России ночью с 4 на 5 декабря 2007 г. в нарушение предписания Европейского Суда от 3 декабря 2007 г. о недопустимости его высылки. Между моментом уведомления властей РФ о необходимости приостановить выдворение в соответствии с Правилом 39 Регламента Суда и вылетом самолета, на котором Камалиев был отправлен в Узбекистан, прошло 26 часов. Суд счел неубедительными доводы правительства о недостатке времени для принятия всех необходимых мер к исполнению предписания Суда и установил, что власти РФ нарушили требования ст. 34 Конвенции, которой закреплено обязательство государств-участников не препятствовать заявителям при осуществлении ими права на обращение в Европейский Суд. Не вызывает сомнений тот факт, что под видом административного выдворения Камалиева власти РФ осуществили незаконную экстрадицию.

Несмотря на то, что ЕСПЧ установил нарушение статьи 34 ЕКПЧ, Особые мнения судей по поводу жалобы на нарушение статьи 8 ЕКПЧ и слабая мотивировка доводов большинства судей вызывают сомнения в обоснованности решения в этой части. Правонарушение, за которое формально было осуществлено административное выдворение, заключалось в нарушении правил регистрации для иностранных граждан. В соответствии с действующим КоАП РФ предусмотренное наказание - штраф, составляющий от 500 до 1000 рублей (примерно от 11 до 23 евро) $)^{17}$. Тогда как такое правонарушение не является уголовно наказуемым деянием, власти отметили длящийся характер правонарушения и отсутствие намерений к легализации своего статуса на территории РФ.

В особом мнении судей Розакиса, Штайнера и Шпильмана акцентируется внимание на неудачном, «автоматическом» применении концепции пределов свободы усмотрения к обстоятельствам дела без рассмотрения вопроса соответствия решения национальных судов вышеупомянутым критериям Унера. К тому же, отдельно следует отметить явную несоразмерность и нарушение главенствующего, в условиях ограничения государственными властями прав и свобод граждан, принципа пропорциональности. Административное правонарушение, предусматри-вающее в качестве наказание незначительный

\footnotetext{
${ }^{17}$ На момент совершения правонарушения действовал Кодекс РФ об административных правонарушениях (КоАП РФ) от 30.12.2001 N 195-Ф3
}

штраф, не может расцениваться как достаточное основание для вмешательства в семейную жизнь супругов. С учетом признания наличия семейных отношений как таковых, крайне непонятны выводы, к которым склонилось большинство судей ЕСПЧ при рассмотрении данного дела.

Европейский Суд по правам человека в своей практике старается избегать безусловных и категоричных выводов. Гибкость подхода ЕСПЧ позволяет ему принимать во внимание уровень социального, правового и технического развития отдельных стран, входящих в Совет Европы. Такой подход, естественно, затрудняет однозначное определение некоторых правовых категорий, вследствие того, что их значения способны изменяться с развитием самого права и общества. Проблема защиты прав мигрантов в свете защиты права на уважение семейной жизни при осуществлении высылки (депортации) остается актуальной, в том числе для нашего государства. Несмотря на то, что в данной области (миграционный контроль, миграционная политика и т.д.) пределы свободы усмотрения национальных властей предельно максимальны, государства, тем не менее, должны обеспечить соответствующий уровень защиты прав и свобод иностранных граждан, вытекающих из их правового статуса, и осуществлять разностороннюю оценку действий силовых структур.

\section{Библиография:}

1. Европейская Конвенция о защите прав человека и основных свобод // http://www.coe.ru/main/echr/

2. Европейская конвенция о защите прав человека и основных свобод. Статья 8 Право на уважение частной и семейной жизни, жилища и корреспонденции. Прецеденты и комментарии. /Урсула Килкэли; пер с англ. Е.А. Чефранова, Москва, 2001.

3. Материалы девятого семинара, проведенного Правозащитным центром «Мемориал» о программе «Миграция и Право»; «Права беженцев в свете гарантий, предусмотренных в Европейской Конвенции по правам человека» М. Б. Лобов ПЦ «Мемориал» М., 2001 г., с .111// http://refugee.memo.ru/site/seminars.nsf/ MainFrame1?OpenFrameSet

4. Постановление Европейского Суда по делу «Абдулазиз, Кабалез и Балкандали против Соединенного Королевства» от 28 мая 1985 г. (№ 9214/80 ; 9473/81 ; 9474/81) // http://www.ourcourt.ru/ practice/feder18/pr18348.htm

5. Постановление Европейского Суда по делу «Бельджуди против Франции» (Beldjoudi v. France) от 26 марта 1992 г. (№ 12083/86) //http://www.echr.ru/ documents/doc/2461457/2461457.htm

6. Постановлении Европейского Суда по делу «Беррехаб против Нидерландов» (Berrehab v Netherlands) от 21 
июня 1988 г. (№ 10730/84) // Информационная система по документам по правам человека и тематическим публикациям / http://www.echr-base.ru/berrehab.jsp)

7. Постановление Европейского Суда по делу “Камалиевы против России” (Kamaliyevy v. Russia) от 3 июня 2010 (жалоба N 52812/07) // http://www. hrights.ru/text/ProgrREFUGEE/REFUGEE/ECHR/ UZBEK/CASE\%20OF\%20KAMALIYEVY\%20v.\%20 RUSSIA RUS.pdf

8. Постановление Европейского Суда по делу «Лю и Лю против Российской Федерации» (Liu v Russia) от 6 декабря 2007 г. (№ 42086/05) //http://www.minjust.ru/ $\mathrm{ru} / \mathrm{ECJ} /$ precedent/index.php?id4=330

9. Постановление Европейского Суда по делу «Мехеми против Франции» (Mehemi v France) от 26 сентября 1997 г. (№ 25017/94) // Бюллетень Европейского Суда по правам человека. Российское издание № 9/2003 г.

10. Постановление Европейского Суда по делу «Фашками против Соединенного Королевства» (Fashkami v United Kingdom) от 22 июня 2004 г. (№ 17341/03) // Бюллетень Европейского Суда по правам человека № $11 / 2004$.

11. Постановление Европейского Суда по делу «Эль Буджайди против Франции» (El Boujaidi v France) от 26 сентября 1996 г. (№ 25613/94) //http://cmiskp.echr. coe.int/tkp197/portal.asp?sessionId $=52615535 \&$ skin $=$ hu doc-en\&action=request

\section{References (transliteration):}

1. Evropeyskaya Konventsiya o zashchite prav cheloveka i osnovnykh svobod // http://www.coe.ru/main/echr/

2. Evropeyskaya konventsiya o zashchite prav cheloveka i osnovnykh svobod. Stat'ya 8 Pravo na uvazhenie chastnoy i semeynoy zhizni, zhilishcha i korrespondentsii. Pretsedenty i kommentarii. /Ursula Kilkeli; per s angl. E.A. Chefranova, Moskva, 2001.

3. Materialy devyatogo seminara, provedennogo Pravozashchitnym tsentrom «Memorial» o programme
«Migratsiya i Pravo»; «Prava bezhentsev v svete garantiy, predusmotrennykh v Evropeyskoy Konventsii po pravam cheloveka» M. B. Lobov PTs «Memorial» M., 2001 g., c .111// http://refugee.memo.ru /site/seminars. nsf/MainFrame1?OpenFrameSet

4. Postanovlenie Evropeyskogo Suda po delu «Abdulaziz, Kabalez i Balkandali protiv Soedinennogo Korolevstva» ot 28 maya 1985 g. (№ 9214/80 ; 9473/81 ; 9474/81) // http:// www.ourcourt.ru/practice/feder18/pr18348.htm

5. Postanovlenie Evropeyskogo Suda po delu «Bel'dzhudi protiv Frantsii» (Beldjoudi v. France) ot 26 marta 1992 g. (№ 12083/86) //http://www.echr.ru/documents/ doc/2461457/2461457.htm

6. Postanovlenii Evropeyskogo Suda po delu «Berrekhab protiv Niderlandov» (Berrehab v Netherlands) ot 21 iyunya 1988 g. (№ 10730/84) // Informatsionnaya sistema po dokumentam po pravam cheloveka i tematicheskim publikatsiyam / http://www.echr-base.ru/berrehab.jsp)

7. Postanovlenie Evropeyskogo Suda po delu «Kamalievy protiv Rossii» (Kamaliyevy v. Russia) ot 3 iyunya 2010 (zhaloba N 52812/07) // http://www.hrights.ru/text/ ProgrREFUGEE/REFUGEE/ECHR/UZBEK/CASE\%20 OF\%20KAMALIYEVY\%20v.\%20RUSSIA_RUS.pdf

8. Postanovlenie Evropeyskogo Suda po delu «Lyu i Lyu protiv Rossiyskoy Federatsii» (Liu v Russia) ot 6 dekabrya 2007 g. (№ 42086/05) //http://www.minjust.ru/ru/ECJ/ precedent/index.php?id4=330

9. Postanovlenie Evropeyskogo Suda po delu «Mekhemi protiv Frantsii» (Mehemi v France) ot 26 sentyabrya 1997 g. (№ 25017/94) // Byulleten’ Evropeyskogo Suda po pravam cheloveka. Rossiyskoe izdanie № 9/2003 g.

10. Postanovlenie Evropeyskogo Suda po delu «Fashkami protiv Soedinennogo Korolevstva» (Fashkami v United Kingdom) ot 22 iyunya 2004 g. (№ 17341/03) // Byulleten’ Evropeyskogo Suda po pravam cheloveka № 11/2004.

11. Postanovlenie Evropeyskogo Suda po delu «El’ Budzhaydi protiv Frantsii» (El Boujaidi v France) ot 26 sentyabrya 1996 g. (№ 25613/94) //http://cmiskp.echr.coe.int/ tkp197/portal.asp?sessionId=52615535\&skin=hudocen\&action=request 